\title{
DRENAGEM SUPERFICIAL DE SOLOS ARGILOSOS DO NORTE DO PARANÁ
}

\author{
Rogério Teixeira de Faria $^{1}$ \& Marcos Vinícius Folegatti ${ }^{2}$
}

\begin{abstract}
RESUMO
Foi avaliado o desempenho de práticas de drenagem superficial e cobertura morta em uma área de várzea do norte do Paraná. Antes e após o cultivo do arroz, foram comparadas as taxas de drenagem em tratamentos com e sem drenos torpedo e determinadas a vazão e a obstrução dos condutos. Sob o cultivo do feijoeiro, foram avaliados os efeitos dos drenos torpedo e de "camas" na drenagem e de cobertura morta (palha de arroz) na retenção de água do solo. Os resultados indicaram que os drenos torpedo foram mais eficientes se construídos com solo menos úmido, porém sua longevidade foi menor que um ano. Sob o feijoeiro, os drenos torpedo e cobertura morta mantiveram o lençol freático mais profundo e o solo com menor tensão de umidade, mas esses efeitos ocorreram abaixo da zona radicular $(15 \mathrm{~cm})$, resultando em baixa produtividade.
\end{abstract}

Palavras-chave: drenos torpedo, drenagem superficial, várzeas, feijão

\section{SUPERFICIAL DRAINAGE FOR CLAY SOIL IN PARANA, BRAZIL}

\begin{abstract}
The performance of surface drainage practices and mulching was evaluated in a low land area in Northern Paraná, Brazil. Before and after rice crop, drainage rates were compared for treatments with and without mole drains, and discharge and clogging of the mole drains were also determined. Under beans, the effects of mole drains and bedding on soil drainage, together with the effect of mulching on soil moisture retention, were evaluated. The results indicated that mole drains were more efficient if constructed under lower soil moisture, however, their longevity was less than one year. During bean cultivation, mole drains and mulching maintained soil water table deeper and lower soil water tension, but these effects occurred in layers deeper than the root zone $(15 \mathrm{~cm})$, resulting in low crop yield.
\end{abstract}

Key words: mole drains, surface drainage, low lands, beans

\section{INTRODUÇÃO}

As áreas de várzea do estado do Paraná apresentam rendimentos elevados e estáveis com a cultura do arroz, que é a mais adaptada. No entanto, faz-se necessário o uso dessas áreas com mais de um cultivo anual, para que se obtenha receita suficiente para amortizar os altos custos iniciais do projeto e os custos operacionais do sistema de produção.
Vários estudos prévios indicaram a viabilidade do uso de várzeas do Paraná com cultivos de sequeiro. Em solos orgânicos do sul do estado, condições adequadas de drenagem possibilitaram a obtenção de produtividades elevadas de feijão (Rosa, 1993) e de trigo e aveia em sucessão ao arroz (Faria \& Postiglioni, 1997). Em solos argilosos do norte do estado, práticas de drenagem superficial associadas com irrigação subterrânea viabilizaram os cultivos de trigo (Calheiros et al., 1991), feijão (Calheiros \& Machado, 1990) e milho e olerícolas (Calheiros, 1994).

\footnotetext{
${ }^{1}$ Pesquisador, IAPAR, Rod. Celso Garcia Cid km 375, CEP 86001 - 970, Londrina, PR, Fax: (043) 3762101

${ }^{2}$ Professor, ESALQ/USP, Av. Pádua Dias 11, CP 9, CEP 13418 - 900, Piracicaba, SP, Fax: (019) 433 0934, E-mail: mvfolega@ carpa.ciagri.usp.br
} 
Nos solos argilosos de várzeas do norte do Paraná, na maioria Gley Pouco Húmico, a má drenagem e a deficiência hídrica limitam os cultivos de sequeiro. Devido à baixa condutividade hidráulica, altas precipitações fazem com que o lençol freático se eleve e permaneça próximo à superfície do solo por períodos relativamente longos. A condição de baixa aeração na zona radicular afeta o crescimento das plantas e resulta em baixa produtividade (Kramer, 1969). Efeitos negativos do excesso hídrico ocorrem também nas microdepressões do terreno, evidenciados pela menor população e crescimento das plantas. Nesses solos, o sistema radicular fica restrito à camada superficial, devido à baixa porosidade do horizonte subsequente (gley). Durante períodos sem precipitação ocorre um rápido secamento da camada superficial, provocando deficiência hídrica, o que também é causa de decréscimo de produtividade.

Para solos argilosos com má drenagem, Schwab et al. (1993) recomendam eliminar o excesso de água via superfície do solo, já que a drenagem interna é limitada, usando métodos de drenagem superficial tais como drenos torpedo e canteiros ou "camas", além de sistematização do terreno, para eliminar as depressões.

Os drenos torpedo apresentam melhor desempenho e maior longevidade quando construídos em solos com teor de argila adequado, situando-se entre 26 a $50 \%$, ou acima de $30 \%$, tendo relação argila/silte maior que 0,5 (Gardner, 1981). Além disso, devem ser construídos a uma profundidade e teor de umidade adequados, para que se obtenha o máximo de fissuras ao redor do conduto e uma perfeita conformação do canal (Cavelaars, 1980; Sommerfeldt, 1983).

Calheiros (1994) realizou um estudo intensivo utilizando drenos torpedo em solo Gley Pouco Húmico da região de Londrina, PR, cuja técnica aumentou a taxa de drenagem, eliminando o excesso hídrico, e possibilitou o suprimento hídrico pela irrigação, utilizando os condutos dos drenos torpedo. O autor recomenda a instalação dos drenos torpedo a uma profundidade de 40 a $50 \mathrm{~cm}$, coincidindo com a camada mais plástica e impermeável do perfil.

A região de Cambará, também no norte do Paraná, apresenta alta concentração de várzeas em produção. Predominam os solos do tipo Gley Pouco Húmico, porém com características distintas do solo do estudo de Calheiros (1994), em que o horizonte A é mais raso, a drenagem é mais lenta e o lençol freático é mais elevado. Nesse solo, devido a má drenagem, a irrigação superficial proporciona excesso hídrico, podendo ocasionar decréscimo de produtividade, e a irrigação subterrânea utilizando os drenos torpedo para condução da água, conforme preconizado por Calheiros (1994), é limitada pela baixa condutividade hidráulica do perfil, além de aumentar o custo de produção. Como alternativa, a cobertura morta pode ser eficiente para aumentar a disponibilidade hídrica do solo, pela diminuição da evaporação, com a vantagem de ser facilmente obtida pela grande disponibilidade de palha de arroz existente nas várzea. Além disso, há necessidade de se investigar se a inundação da área para irrigação do arroz durante o verão poderia causar obstrução dos canais dos drenos torpedo previamente instalados, devido ao colapso das paredes dos condutos em condições saturadas.

O presente trabalho teve como objetivo determinar a longevidade e a eficiência de drenagem de drenos torpedo, além de avaliar o desempenho de práticas de drenagem superficial e cobertura morta, para minimizar os efeitos de excesso e déficit hídrico em área de solos argilosos da região de Cambará, PR, cultivada com feijão em sucessão ao arroz.

\section{MATERIAL E MÉTODOS}

Os trabalhos foram conduzidos na Estação Experimental do IAPAR, em Cambará, PR, em área sistematizada e drenada por canais abertos de $100 \mathrm{~m}$ de comprimento, espaçados de $40 \mathrm{~m}$ e com profundidade de $1 \mathrm{~m}$. O clima da região é do tipo Cfa e o solo da área foi classificado como sendo Gley Pouco Húmico eutrófico, textura argilosa, relevo plano (concrecionário). A determinação da condutividade hidráulica pelo método do poço (van Beers, 1958) apresentou o valor médio de $10^{-3} \mathrm{~m} \mathrm{dia}^{-1} \mathrm{e}$ as análises químicas e físicas apresentaram elevada concentração de macronutrientes e baixa saturação de alumínio, porém com acentuada restrição de aeração a partir de $10 \mathrm{~cm}$.

O estudo foi conduzido durante dois anos e consistiu dos seguintes experimentos:

\section{Avaliação da eficiência de drenagem e determinação da longevidade de drenos torpedo}

Os tratamentos foram avaliados em parcelas em três repetições. Os drenos torpedo foram construídos com um subsolador constituído de um cilindro de ferro de $5 \mathrm{~cm}$ de diâmetro, acoplado por uma corrente a um expansor com diâmetro $7,5 \mathrm{~cm}$ e soldado a uma haste de ferro cortante de espessura e comprimento de $2 \mathrm{~cm} \mathrm{e} 0,6 \mathrm{~m}$, respectivamente, conforme descrito por Calheiros (1994). A estrutura foi sustentada por um chassi com engates em três pontos para ser tracionado por um trator de porte médio e os condutos foram construídos a $0,4-0,5 \mathrm{~m}$ de profundidade, espaçados de $3,5 \mathrm{~m}$ e diâmetro de $7,5 \mathrm{~cm}$. Procedeu-se à orientação dos drenos torpedo em direção perpendicular aos canais existentes na área, fazendo-se suas saídas no canal localizado na parte mais baixa do bloco e escolheu-se a época mais seca do ano (julho), a fim de assegurar condição de baixa umidade do solo.

A eficiência de drenagem e a longevidade dos drenos torpedo foram avaliadas antes e após a inundação da área para a irrigação do arroz, aos 8 meses e um ano após a construção dos drenos torpedo, respectivamente. Determinou-se a taxa de rebaixamento do lençol freático nos tratamentos com e sem torpedo, após a saturação do solo pela inundação do terreno até a formação de uma lâmina de água, de cerca de $10 \mathrm{~cm}$. Após atingir a lâmina desejada, procedeu-se à drenagem da água superficial pela abertura das comportas existentes nos canais de drenagem. A seguir, e a partir da saturação, determinou-se a velocidade de rebaixamento do lençol freático medindo-se o nível da água em poços de observação de $1,2 \mathrm{~m}$ de profundidade e $25 \mathrm{~mm}$ de diâmetro. Utilizaram-se 30 poços de observação por tratamento, estrategicamente instalados entre os drenos torpedo ao longo das parcelas.

Simultaneamente às determinações de nível de lençol freático, procedeu-se à medição da vazão na saída dos drenos torpedo, utilizando-se proveta graduada e cronômetro. Investigou-se, também, o nível de obstrução dos condutos pela observação direta em trincheiras abertas ao acaso. A longevidade dos drenos 
torpedo foi determinada pelo julgamento da necessidade de abertura de novos condutos, caso a eficiência de drenagem tenha sido decrescida consideravelmente.

\section{Eficiência do sistema de drenagem superficial e cobertura morta durante o ciclo de desenvolvimento do feijoeiro}

Foram avaliados os seguintes tratamentos usando-se um delineamento em parcela sub-subdividida, com três repetições:

- Sistemas de drenagem (parcela)

a) Com torpedo

b) Drenagem

- Sistematização (subparcela)

a) "Camas"

b) Sistematização nível zero

- Tipo de cobertura (sub-subparcela)

a) Cobertura morta

b) Sem cobertura morta

As sub-subparcelas tiveram área útil com dimensões de $8 \mathrm{~m}$ por $20 \mathrm{~m}$. Os drenos torpedo foram os mesmos utilizados na avaliação anterior e as "camas" constituíram-se de canteiros espaçados de $0,8 \mathrm{~m}$, com $20 \mathrm{~m}$ de comprimento, 1,2 m de largura e $0,2 \mathrm{~m}$ de altura. Foram construídas manualmente, após o preparo do solo com arado de disco, seguido de destorroamento com enxada rotativa. Para a cobertura morta utilizou-se palha de arroz existente na área, fazendo-se uma camada de cerca de $5 \mathrm{~cm}$ de espessura.

O feijoeiro foi semeado em início de agosto, utilizando-se a cultivar Carioca em espaçamento de $0,5 \mathrm{~m}$ e densidade de 12 plantas $\mathrm{m}^{-1}$ nas parcelas com sistematização nível zero e $0,4 \mathrm{~m}$ e 12 plantas $\mathrm{m}^{-1}$ sobre as "camas" (4 linhas por "cama") para se obter a mesma população por área. Foram aplicados 4,60 e $20 \mathrm{~kg} \mathrm{ha}^{-1}$ de $\mathrm{N}, \mathrm{P}_{2} \mathrm{O}_{5}$ e $\mathrm{K}_{2} \mathrm{O}$, respectivamente, no sulco de semeadura e $20 \mathrm{~kg} \mathrm{ha}^{-1}$ de $\mathrm{N}$ em cobertura aos 20 dias após a emergência. A cultura foi conduzida livre de competição com ervas daninhas, pragas e doenças.

A tensão de água no solo foi determinada durante o ciclo do feijoeiro, usando-se tensiômetros instalados a $10 \mathrm{~cm} \mathrm{de}$ profundidade. As leituras foram realizadas a cada 3 a 4 dias, juntamente com as determinações do nível do lençol freático, determinado em poços de observação instalados nos vários tratamentos. Os efeitos dos tratamentos foram avaliados por determinações da produtividade do feijoeiro, nível do lençol freático e tensão de água no solo durante o desenvolvimento da cultura.

\section{RESULTADOS E DISCUSSÃO}

\section{Eficiência de drenagem e longevidade dos drenos torpedo}

Por ocasião da construção dos drenos torpedo, em julho do primeiro ano, o solo apresentava-se bastante seco devido a um longo período de estiagem, condição esta altamente favorável, sendo possível obter-se uma boa formação do conduto de drenagem. Observou-se, também, que a potência para tração do implemento foi relativamente baixa (menor que $50 \mathrm{cv}$ ). Nas partes mais secas do terreno o esforço de tração foi mais alto que nas partes úmidas sendo, porém, compensado pela maior aderência da máquina com o solo seco. Nas partes úmidas o patinamento do trator não foi considerável, devido ao menor esforço exigido.
Os resultados de eficiência de drenagem dos tratamentos com e sem drenos torpedo em diferentes épocas encontram-se na Figura 1. A variação do nível de lençol freático com o tempo na primeira determinação, realizada antes do cultivo do arroz, mostrou que houve efeito positivo dos drenos torpedo na velocidade de drenagem (Figura 1A). O nível de lençol freático foi sempre mais profundo na área com torpedo, atingindo cerca de $20 \mathrm{~cm}$ de profundidade após $15 \mathrm{~h}$ de drenagem, enquanto na área sem dreno torpedo o nível do lençol freático foi de cerca de $10 \mathrm{~cm}$ para o mesmo tempo. Porém, os resultados obtidos na determinação realizada após a inundação da área para irrigação do arroz demonstraram não haver diferenças de nível do lençol freático com o tempo nas áreas com e sem torpedo (Figura 1B). A vazão dos drenos torpedo decresceu a quase zero, comparada com valores de 2 a $4 \mathrm{~L} \mathrm{~min}^{-1}$ após $15 \mathrm{~h}$ de drenagem na determinação anterior (Figura 2), em que a causa da queda de eficiência de drenagem foi atribuída à obstrução dos canais com raízes de arroz e sedimentos durante a manutenção do terreno saturado com a lâmina de irrigação aplicada na cultura do arroz, comprovada pela abertura de trincheiras nas áreas com drenos torpedo.

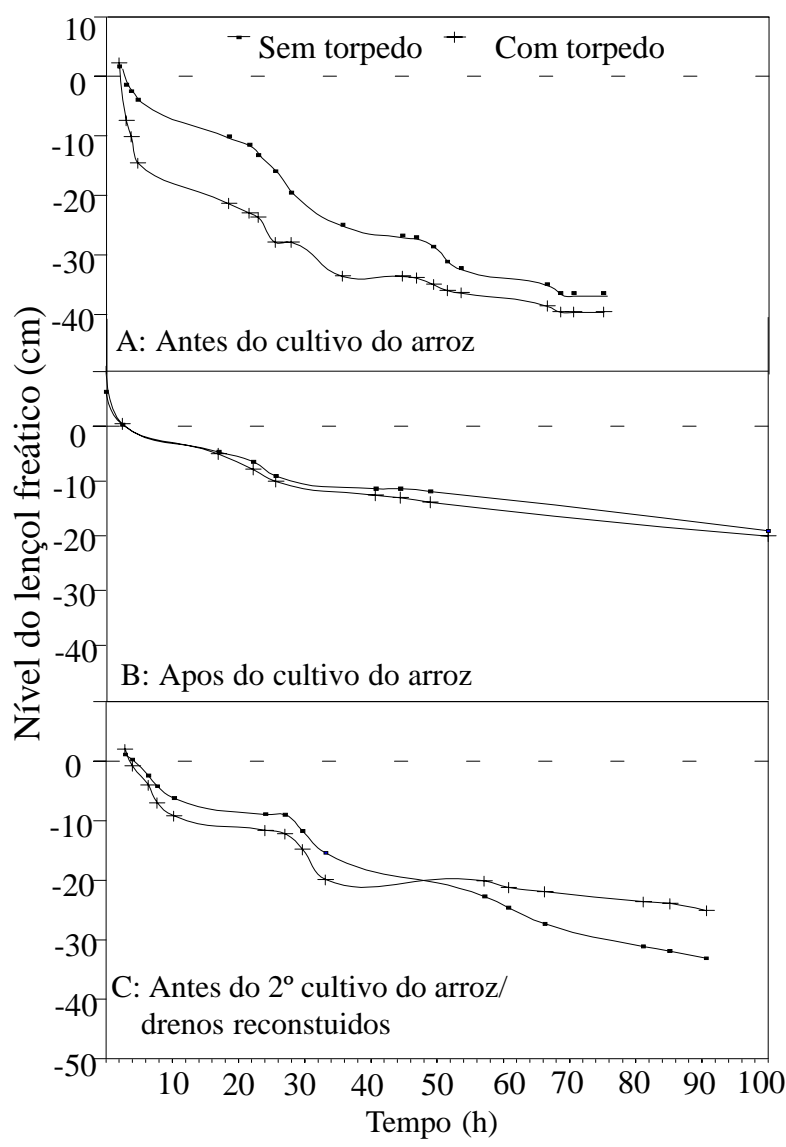

Figura 1. Nível médio do lençol freático em função do tempo de drenagem nas áreas com e sem torpedo para diferentes épocas de determinação

Constatada a obstrução dos canais, realizou-se a construção de novos drenos torpedo, ao lado dos já existentes, antes da semeadura do feijão, em agosto. Os resultados da determinação realizada posteriormente, antes da inundação da área para o segundo cultivo de arroz, indicaram maior taxa de rebaixamento do lençol freático no tratamento com torpedo comparada com a 
determinada no tratamento sem torpedo (Figura 1C). Porém, a diferença entre os tratamentos foi menos evidente e houve decréscimo da vazão dos drenos torpedo (Figura 2) em relação à determinação do ano anterior. Atribuiu-se, a este resultado, o fato da construção dos drenos torpedo ter sido realizada com o terreno úmido, não apresentando as condições adequadas para a formação do conduto de drenagem, como no ano anterior. As trincheiras abertas na área, nesta época, confirmaram a obstrução dos condutos por sedimentos em alguns dos drenos.

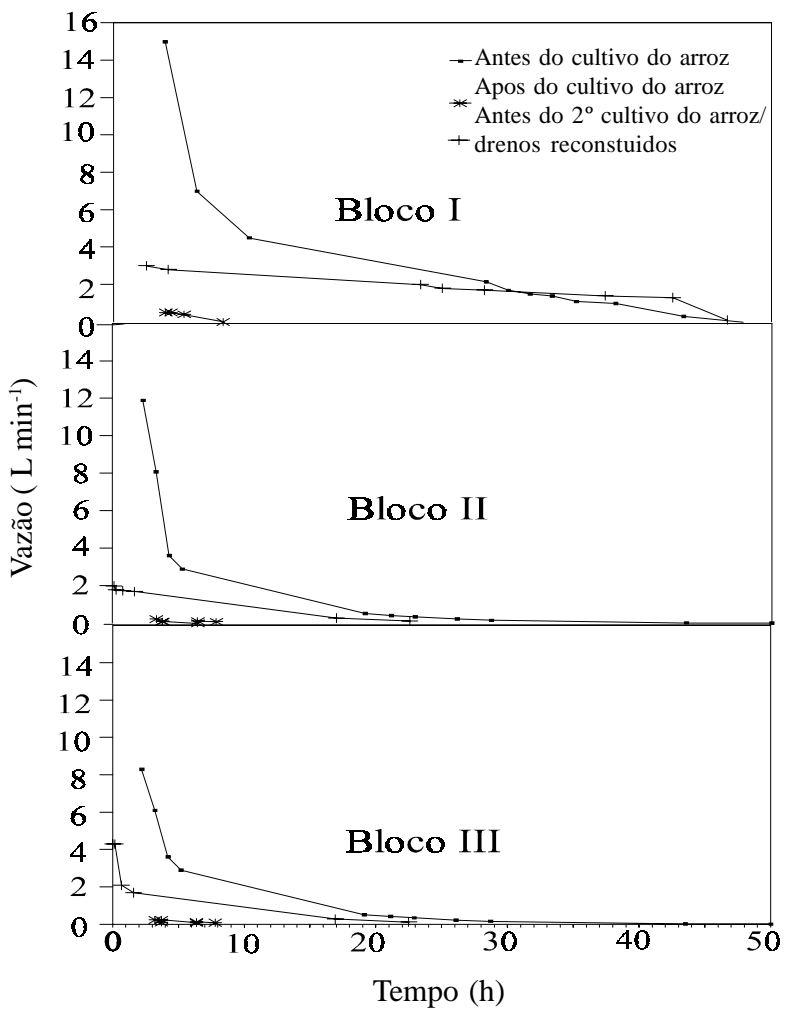

Figura 2. Vazão média dos drenos torpedo em função do tempo de drenagem para diferentes blocos e épocas de determinação

\section{Eficiência dos sistemas de drenagem superficial e cobertura morta na cultura do feijoeiro}

A avaliação dos efeitos dos tratamentos na cultura do feijoeiro no primeiro ano de cultivo foi prejudicada devido à estiagem, que se prolongou durante quase todo o ciclo, o que impossibilitou a obtenção de dados de produtividade de feijoeiro. Não foi notado, também, efeito favorável da cobertura morta nestas condições, devido ao prolongado período de deficiência hídrica.

Os efeitos dos sistemas de drenagem superficial e cobertura morta nos níveis de lençol freático durante o cultivo do feijão no segundo ano de cultivo são apresentados na Figura 3. Observa-se que as áreas com drenos torpedo apresentaram níveis de lençol freático ligeiramente mais profundos e menores picos de elevação do lençol freático com a ocorrência de precipitação (Figura 3A). As diferenças em agosto foram devidas à longa estiagem e à melhor drenagem natural da área sem torpedo, efeito este corrigido com o início da estação chuvosa, no início de setembro, cujos resultados demonstram ainda que não houve efeito evidente da sistematização do solo (Figura 3B) nem da cobertura morta (Figura 3C) no nível de lençol freático.

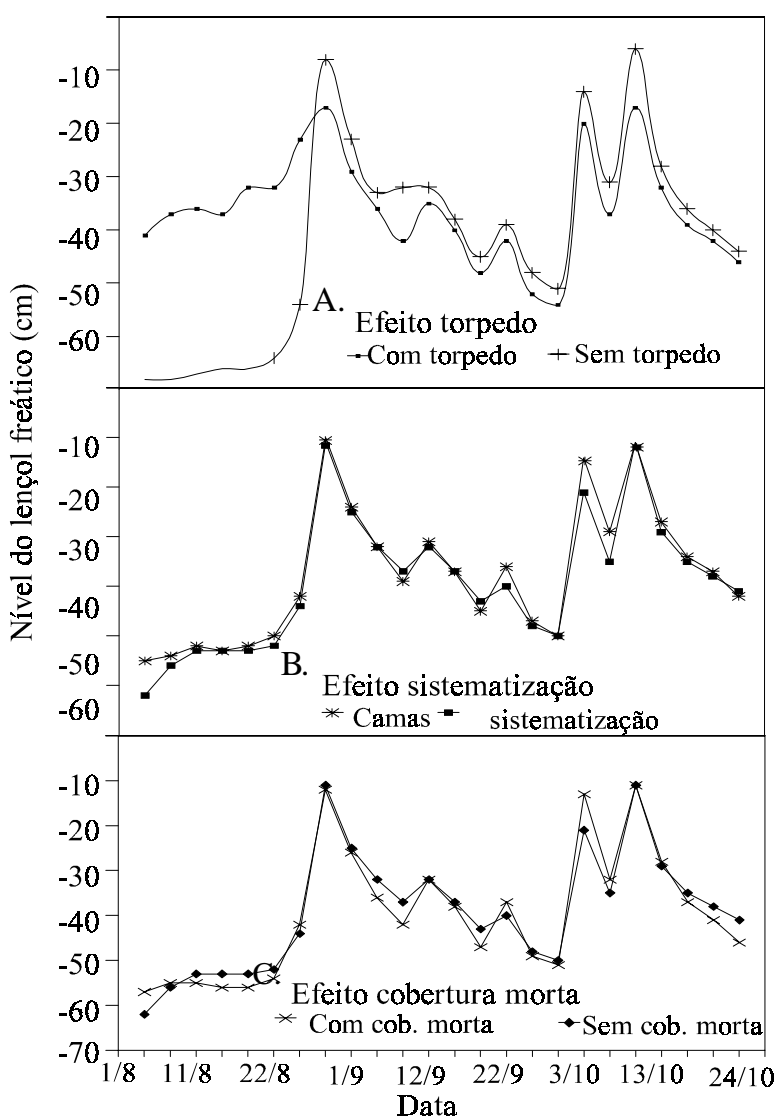

Figura 3. Efeitos dos sistemas de drenagem superficial e cobertura morta no nível do lençol freático durante o cultivo do feijoeiro

Os efeitos dos sistemas de drenagem superficial e cobertura morta na tensão de água do solo durante o cultivo do feijão são apresentados na Figura 4. Os resultados indicam que somente o tratamento com cobertura morta teve algum efeito no parâmetro analisado (Figura 4C). Menores valores de tensão foram medidos no tratamento com cobertura morta, em relação ao tratamento sem cobertura morta, principalmente durante o período seco, ocorrido no mês de setembro. Observou-se grande variação da tensão durante a condução da cultura em todos os tratamentos, ocorrendo valores próximos à saturação do solo, por períodos relativamente longos após a ocorrência de precipitação (25 de agosto a 5 de setembro e meados de outubro) e elevação da tensão durante o período sem precipitação (meados de setembro a meados de outubro).

Observações durante a condução da cultura permitiram constatar que o sistema radicular concentrou-se nos primeiros $15 \mathrm{~cm}$, em decorrência das limitações naturais de aeração do horizonte gley, mesmo na ausência do lençol freático. Esta característica, associada às condições de excesso e déficit hídrico, limitou consideravelmente o crescimento da cultura. $\mathrm{O}$ menor crescimento nos períodos úmidos pode ser atribuído ao estresse devido à saturação da zona radicular, causada pela rápida elevação do lençol freático, mesmo após baixa lâmina de precipitação. Durante o período seco constataram-se sintomas evidentes de estresse hídrico, resultando em baixo crescimento das plantas, embora a tensão medida não tenha sido elevada. Os valores de tensão não foram mais elevados porque foram medidos na transição da camada arável com o horizonte gley. Durante os períodos sem precipitação observou-se um gradiente 
de umidade considerável, na posição de medida da tensão (10 $\mathrm{cm}$ de profundidade) sendo a camada inferior sempre mais úmida e a camada superficial muito seca. Como há uma grande descontinuidade de poros entre os horizontes, o fluxo capilar ascendente é insuficiente para suprir as perdas por evaporação da camada superficial, o que conserva a umidade da camada gley e resulta na baixa umidade da camada superficial. Consequentemente, o estresse hídrico decorre da concentração das raízes no horizonte superficial.

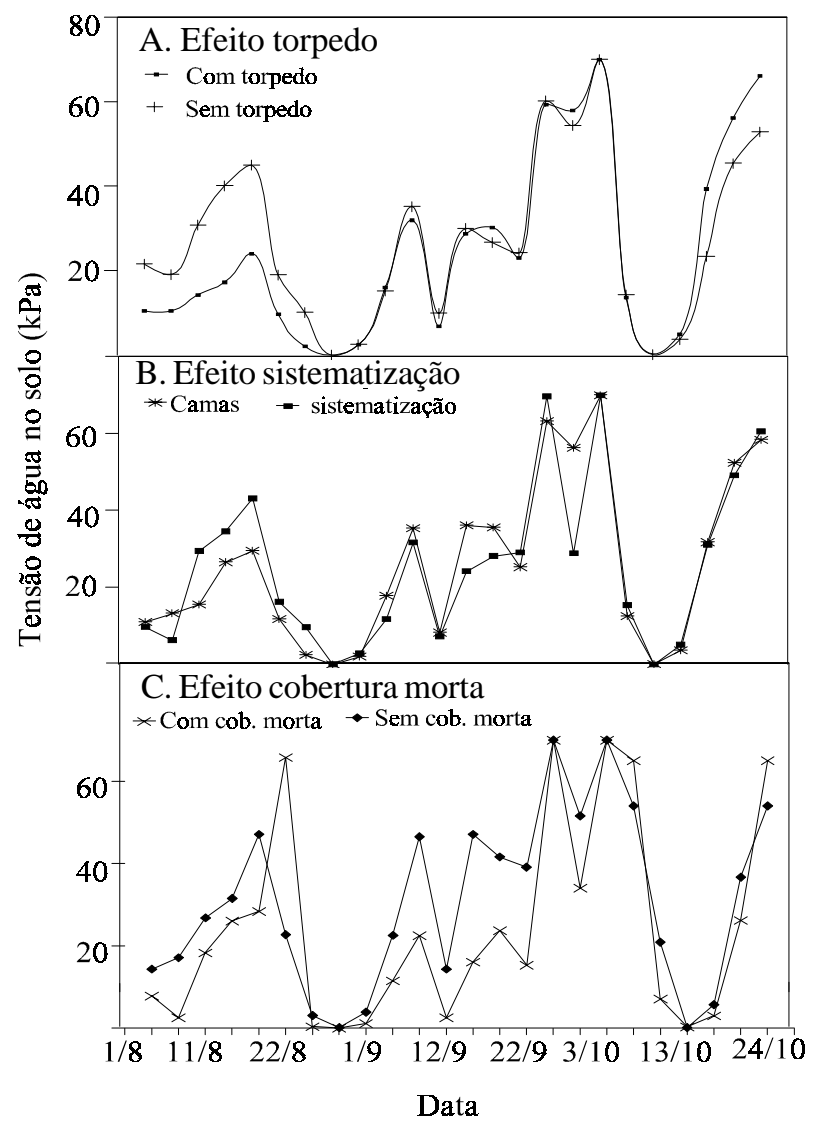

Figura 4. Efeitos dos sistemas de drenagem superficial e cobertura morta na tensão de água do solo durante o cultivo do feijoeiro

Dada a condição de solo e a resultante distribuição do sistema radicular, os tratamentos de drenagem superficial e cobertura morta testados foram ineficientes para minimizar os efeitos do estresse, causado pelo excesso e pela deficiência hídrica, porque tiveram efeito em profundidade maior que a compreendida pelo sistema radicular. Consequentemente, as condições desfavoráveis de umidade do solo verificadas na zona radicular tiveram efeito prejudicial na produtividade de grãos de feijão, conforme Tabela 1. A produtividade obtida foi muito mais baixa que a relatada por Calheiros \& Machado (1990) evidenciando a dificuldade de manejo de solos de várzeas com horizonte superficial raso e lençol freático elevado, como o solo desse estudo.

Tabela 1. Efeitos dos sistemas de drenagem superficial e cobertura morta na produtividade de feijão $\left(\mathrm{kg} \mathrm{ha}^{-1}\right)$, em Cambará, PR

\begin{tabular}{lcc}
\hline Tratamento & Com & Sem \\
\hline Torpedo & 443 & 365 \\
Sistematização $^{1}$ & 353 & 405 \\
Cobertura morta $^{1}$ & 397 & 419 \\
\hline
\end{tabular}

'Sem = sistematização nível zero; Com = "camas"

\section{CONCLUSÕES}

1. A Condição de baixa umidade do solo foi fundamental para a construção de drenos torpedo eficientes para promover o rebaixamento do lençol freático em várzeas de solos argilosos.

2. A longevidade dos drenos torpedo foi menor que um ano devido à obstrução dos condutos por raízes e sedimentos durante o período de irrigação do arroz.

3. Os drenos torpedo não influenciaram a tensão de água no solo, porém mantiveram o lençol freático mais profundo e decresceram os picos de elevação do lençol freático durante os períodos chuvosos, enquanto a cobertura morta manteve o terreno com menores tensões durante os períodos secos.

4. Ocorreu baixa produtividade do feijoeiro em razão do excesso e déficit hídrico decorrentes da limitação de aeração do solo ao aprofundamento do sistema radicular.

5. Os tratamentos de drenagem superficial e cobertura morta testados foram ineficientes para minimizar as condições desfavoráveis de umidade para a cultura do feijão porque tiveram efeito em profundidades maiores que a do sistema radicular.

\section{REFERÊNCIAS BIBLIOGRÁFICAS}

CALHEIROS, R. de O. Exploração agrícola de solos minerais de várzeas (Gley Pouco Húmico) utilizando o sistema de drenagem tipo torpedo. Londrina: IAPAR, 1994. IAPAR, Boletim Técnico, 44

CALHEIROS, R. de O.; FARIA, R.T. de; MACHADO, P. Exploração da cultura do trigo (Triticum aestivum L.) em sucessão ao arroz em solo Gley Pouco Húmico. Revista de Engenharia Rural, Piracicaba, v. 2, p.1-18, 1991.

CALHEIROS, R. de O.; MACHADO, P. Introdução da cultura do feijão (Phaseolus vulgaris, L.) em várzea de solo Gley Pouco Húmico através do dreno torpedo e sistema de sulcos de infiltração. ITEM - Irrigação e Tecnologia Moderna, Brasília, v. 40, p.32-9, 1990.

CAVELAARS, J.C. Subsurface field drainage systems. In: ILRI, Drainage principles and applications. Wageningen, ILRI, 1980. v. IV, $470 \mathrm{p}$.

FARIA, R.T de; POSTIGLIONI, S.R. Avaliação de cultivos de inverno em sucessão com arroz em várzeas. Revista Engenharia Agrícola, Jaboticabal, v.16, n.4 p.11-21, 1997.

GARDNER, M.J. Land drainage. Program of Coordination of Research and Land Use \& Rural Resources. Cambridge-UK, 1981. 127 p.

KRAMER, P.J. Plant and soil relationships: A modern synthesis. New York: McGraw-Hill, 1969.482p

ROSA, J.A. Níveis de drenagem para a cultura do feijoeiro em várzeas. Pesquisa Agropecuária Brasileira. Brasília, v.28 n.8, p.947-54, 1993.

SCHWAB, G.O.; FANGMEIER, D.D.; ELLIOT, W.J.; FREVERT, R.K. Soil and water conservation engineering. New York, Jonh Willey \& Sons, 1993. 507 p.

SOMMERFELDT, G. Soil moisture and texture effects on mole drain stability and on force requirement for installation laboratory study. Canadian Agricultural Engineering, Ottawa, v.25, n.1, p.1-4, 1983.

van BEERS, W.F.J. The auger hole method. Wageningen: International Institute for Land Reclamation and Improvement. 1958. 32 p. Bulletin No. 1 